\title{
CD1d deficiency limits tolerogenic properties of peritoneal macrophages
}

\author{
Fathihah Basri ${ }^{1, \#}$, Sundo Jung ${ }^{2, \#}$, Se Hoon Park ${ }^{1} \mathcal{E}$ Se-Ho Park ${ }^{1, *}$ \\ ${ }^{1}$ Department of Life Sciences, Korea University, Seoul 02841, ${ }^{2}$ Department of Biomedical Laboratory Science, Shinhan University, \\ Uijeongbu 11644, Korea
}

Invariant natural killer T (iNKT) cells are involved in various autoimmune diseases. Although iNKT cells are arthritogenic, transforming growth factor beta (TGF $\beta$ )-treated tolerogenic peritoneal macrophages (Tol-pM $\varphi$ ) from wild-type (WT) mice are more tolerogenic than those from CD1d knock-out iNKT cell-deficient mice in a collagen-induced arthritis (CIA) model. The underlying mechanism by which $\mathrm{pM} \varphi$ can act as tolerogenic antigen presenting cells (APCs) is currently unclear. To determine cellular mechanisms underlying CD1d-dependent tolerogenicity of $\mathrm{pM} \varphi$, in vitro and in vivo characteristics of $\mathrm{pM} \varphi$ were investigated. Unlike dendritic cells or splenic $\mathrm{M} \varphi, \mathrm{pM} \varphi$ from $\mathrm{CD}^{+/-}$mice showed lower expression levels of costimulatory molecule CD86 and produced lower amounts of inflammatory cytokines upon lipopolysaccharide (LPS) stimulation compared to $\mathrm{pM} \varphi$ from CD1d-deficient mice. In a CIA model of CD1d-deficient mice, adoptively transferred $\mathrm{pM} \varphi$ from $\mathrm{WT}$ mice reduced the severity of arthritis. However, $\mathrm{pM} \varphi$ from CD1d-deficient mice were unable to reduce the severity of arthritis. Hence, the tolerogenicity of $\mathrm{pM} \varphi$ is a cell-intrinsic property that is probably conferred by iNKT cells during $\mathrm{pM} \varphi$ development rather than by interactions of $\mathrm{pM} \varphi$ with iNKT cells during antigen presentation to cognate T cells. [BMB Reports 2021; 54(4): 209-214]

\section{INTRODUCTION}

T cell receptor (TCR) complexes of conventional $\mathrm{CD}^{+}$and $\mathrm{CD} 8^{+}$ $\mathrm{T}$ cells are known to generate essential biochemical signals to initiate $\mathrm{T}$ cell immunity upon recognizing antigenic peptides derived from lysosomal or proteosomal proteolytic processing. Antigenic peptides are presented by major histocompatibility

*Corresponding author. Tel: +82-2-3290-3160; Fax: +82-2-927-9028; E-mail: sehopark@korea.ac.kr

${ }^{\#}$ These authors contributed equally to this work.

https://doi.org/10.5483/BMBRep.2021.54.4.183

Received 31 August 2020, Revised 19 September 2020, Accepted 10 December 2020

Keywords: CD1d, CIA, NKT cells, Peritoneal macrophage, Rheumatoid arthritis complex (MHC) molecules widely expressed on professional antigen presenting cells (APCs) including dendritic cell (DCs), macrophages, and B cells $(1,2)$. In contrast to conventional T cell activation, invariant natural killer T (iNKT) cells can recognize lipid or glycolipid antigens presented on CD1d, an MHC class I (MHC-I)-like molecule, and show prolonged cytokine production upon activation (3). CD1d is a cell surface glycoprotein comprising a heavy chain in non-covalent association with a $\beta 2$-microglobulin light chain. It is broadly expressed in lymphoid and myeloid cells (4). iNKT cells can be distinguished based on their TCR expression. They share some markers such as CD161 (NK1.1 in mice) and NKR-P1 that are characteristics of natural killer cells (3). iNKT cells can produce a wide variety of cytokines including proinflammatory and anti-inflammatory cytokines with multiple effects on the outcome of immune reactions (5). iNKT cells can also be activated in the absence of foreign microbial challenges, suggesting that they might occupy some immunological niches under immunologically quiet time and inflammatory condition (6).

During the past several years, regulatory and autoimmune roles of iNKT cells have been characterized. However, contrasting results have been observed using various approaches pertaining to iNKT cell-targeted treatments. It is currently unclear whether their effects are beneficial or detrimental to the host $(5,7,8)$. Differing effects of iNKT cells in various systems reflect their ability to inform or influence functions of APCs (6). It has been recently shown that iNKT cells can reverse suppressive types of regulatory APCs known as myeloid-derived suppressor cells (MDSCs) into DCs to stimulate Th1 T cell responses (9). However, repeated administration of $\alpha$-Galcer can result in an exhausted phenotype of iNKT cells that provides altered signals to DC and induces regulatory DC phenotypes that can prevent the onset of autoimmunity and silence autopathogenic T cells (10). Other studies have shown that CD1d-dependent iNKT cells play crucial roles in reducing joint inflammation (11). These effects were correlated with other autoimmune diseases such as experimental autoimmune encephalomyelitis (EAE) (12).

Macrophages play pivotal roles in rheumatoid arthritis (RA). They are prevalent in inflamed synovial membranes and at the cartilage-pannus junction. These cells possess broad proinflammatory, destructive, and remodeling capacities that contribute to

ISSN: 1976-670X (electronic edition)

Copyright (c) 2021 by the The Korean Society for Biochemistry and Molecular Biology

(c) This is an open-access article distributed under the terms of the Creative Commons Attribution Non-Commercial License (http://creativecommons.org/licenses/by-nc/4.0) which permits unrestricted non-commercial use, distribution, and reproduction in any medium, provided the original work is properly cited. 
acute and chronic phases of RA. Previously, it has been demonstrated that augmented recruitment and enhanced function of APCs are key steps associated with innate and adaptive immunity (13).

We have previously reported that TGF $\beta$-treated tolerogenic $\mathrm{pM} \varphi$ from $\mathrm{CD} 1 \mathrm{~d}^{+/-}$mice, but not from CD1d KO (iNKT celldeficient) mice, can facilitate APC-mediated suppression of CIA (14). In this study, we expanded these initial findings and investigated capabilities of $\mathrm{pM} \varphi$. We found that their characteristics as tolerogenic APCs to suppress CIA were mostly cell-intrinsic rather than caused by TGF $\beta$ treatment.

\section{RESULTS}

\section{Involvement of iNKT cells in anti-inflammatory phenotypes of peritoneal macrophages}

iNKT cells not only can regulate local immune effector functions, but also can promote or inhibit priming of adaptive immune responses by releasing cytokines to induce APCs toward immunogenic or tolerogenic phenotypes (10). Tolerogenic effects of TGF- $\beta_{2}$-treated APCs (Tol-APCs) require iNKT cells to mediate the suppression of CIA (14). Based on these findings, we initially determined whether $\mathrm{pM} \varphi$ from $\mathrm{CD} 1 \mathrm{~d}^{+/-}$mice and $\mathrm{CD} 1 \mathrm{~d}^{-/-}$ (iNKT cell-deficient) mice possessed intrinsic variances that might contribute to differential responses of CIA. Results validated previous findings, demonstrating that transfer of $\mathrm{pM \varphi}$ from $\mathrm{CD}_{1} \mathrm{~d}^{+/-}$ mice lowered incidences and clinical CIA scores compared to transfer of $\mathrm{pM} \varphi$ from $\mathrm{CD} 1 \mathrm{~d}^{-/-}$mice (Fig. 1). These results sug-
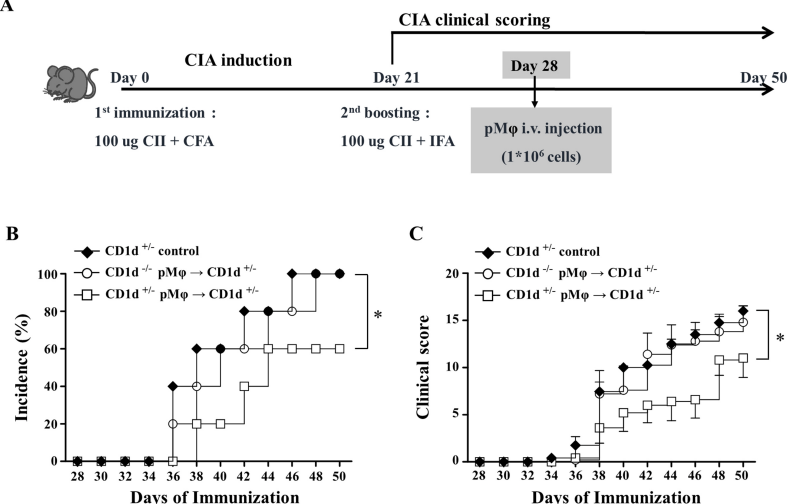

Fig. 1. $\mathrm{CD}_{1} \mathrm{~d}^{+/-} \mathrm{pM} \varphi$ suppresses collagen-induced arthritis. (A) Experimental schedules. To induce CIA, CD1d ${ }^{+/-}$mice were immunized using intradermal tail base injections of $100 \mu \mathrm{g}$ of chicken Cll emulsified with an equal volume of CFA. Three weeks later, mice were i.d. boosted with $100 \mu \mathrm{g}$ of CII in IFA. Seven days later, mice received intravenous injections of $1 \times 10^{6} \mathrm{CD}^{-1-} \mathrm{pM} \varphi(O), \mathrm{CD}^{+1-}$ pM $\varphi(\square)$, or PBS as CIA control $($ ). (B) Incidence of arthritic mice; (C) Clinical scores of arthritis in each group. Paws were scored from 0 to 5 according to the severity of arthritis, with a maximum cumulative score of 20 . Results are presented as means \pm SEM from three independent assessments (5 mice per group) of inflammation scores (0-5). gest that iNKT cells might be involved in the tolerogenicity of $\mathrm{CD} 1 \mathrm{~d}^{+/-} \mathrm{pM} \varphi$. Therefore, we further assessed characteristics of these cells from CD1d $\mathrm{d}^{+-}$and $\mathrm{CD} 1 \mathrm{~d}^{-1-}$ mice by observing changes in costimulatory molecule expression with or without LPS stimulation. Results showed that CD86 levels were significantly lower in $\mathrm{pM} \varphi$ from $\mathrm{CD} 1 \mathrm{~d}^{+/-}$mice. However, there was no significant difference in MHC II level (Fig. 2A). Other markers such as CD11C, CD80, CD206, F4/80, PD-L1, and PD-L2 showed no significant difference in their expression between $\mathrm{pM} \varphi$ from $\mathrm{CD}_{1 \mathrm{~d}^{+/-}}$mice and $\mathrm{pM} \varphi$ from $\mathrm{CD} 1 \mathrm{~d}^{-/-}$mice (Supplementary Fig. 1). There were no significant differences in the expression of CD1d, MHC II, CD11b, CD80, or CD86 either between $\mathrm{pM} \varphi$ and Tol-pM $\varphi$ (data not shown). Secretion of inflammatory cytokines such as TNF- $\alpha$ and IL- 6 was markedly reduced in $\mathrm{pM} \varphi$ from $\mathrm{CD} 1 \mathrm{~d}^{+/-}$mice compared to that in $\mathrm{pM} \varphi$ from $\mathrm{CD}_{1 \mathrm{~d}^{-/-}}$mice after LPS stimulation (Fig. 2B). In contrast, secretion of anti-inflammatory IL-10 in $\mathrm{pM} \varphi$ from $\mathrm{CD}_{1} \mathrm{~d}^{+/-}$ mice was significantly higher than that in $\mathrm{pM} \varphi$ from $\mathrm{CD} 1 \mathrm{~d}^{-1-}$ mice (Fig. 2B), further suggesting that differences in $\mathrm{pM} \varphi$ between $\mathrm{CD} 1 \mathrm{~d}^{+/-}$and $\mathrm{CD} 1 \mathrm{~d}^{-1-}$ mice were probably associated with the presence or absence of iNKT cells during pM $\varphi$ maturation.

\section{$\mathrm{CD}^{+/-}$peritoneal macrophages attenuate in vitro $\mathrm{CD4}^{+} \mathrm{T}$ cell activation}

To confirm tolerogenic phenotypes of $\mathrm{pM} \varphi$ from $\mathrm{CD} 1 \mathrm{~d}^{+/-}$mice, in vitro CD4 T cell-stimulating capacities of $\mathrm{pM} \varphi$ as APCs were measured. To this end, we isolated and cocultured OVA-specific TCR transgenic OT-II CD4 T cells with OVA-loaded $\mathrm{pM} \varphi$ from $\mathrm{CD} 1 \mathrm{~d}^{-1-}$ and $\mathrm{CD} 1 \mathrm{~d}^{+/-}$littermate mice for $72 \mathrm{~h}$ in vitro.

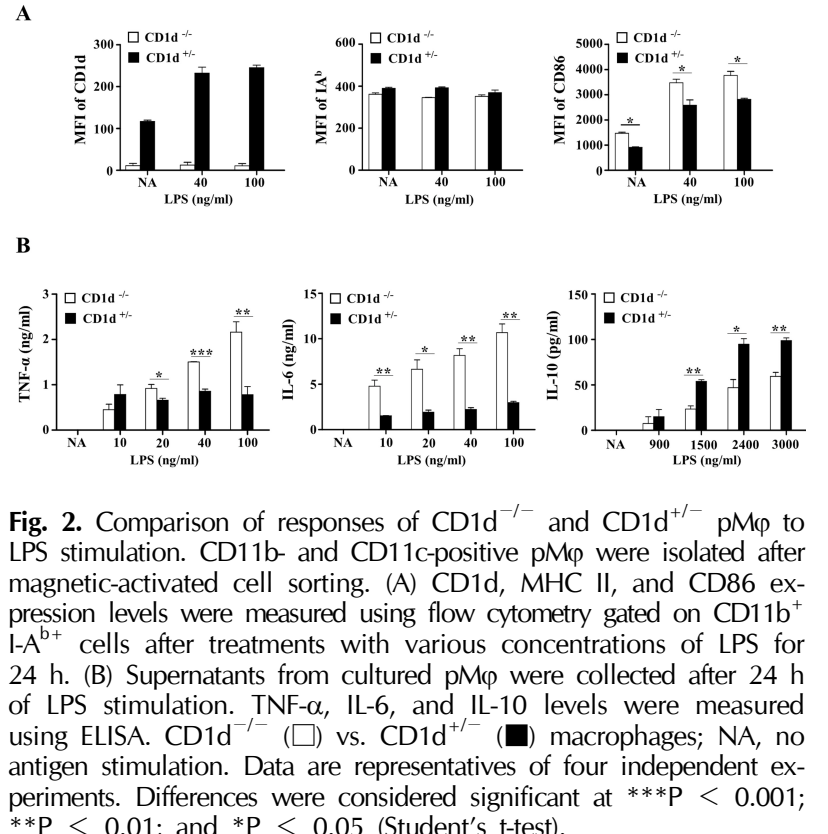
pMexpression levels were measured using flow cytometry gated on CD11 $\mathrm{b}^{+}$ $\mathrm{I}-\mathrm{A}^{\mathrm{b}+}$ cells after treatments with various concentrations of LPS for $24 \mathrm{~h}$. (B) Supernatants from cultured $\mathrm{pM} \varphi$ were collected after $24 \mathrm{~h}$ of LPS stimulation. TNF- $\alpha$, IL-6, and IL-10 levels were measured using ELISA. CD1d ( $\square)$ vs. CD1d ${ }^{-1}(\square)$ macrophages; NA, no periments. Differences were considered significant at $* * * P<0.001$; $* * \mathrm{P}<0.01 ;$ and $* \mathrm{P}<0.05$ (Student's t-test). 
TGF $\beta_{2}$-treated $\mathrm{pM} \varphi$ from $\mathrm{CD} 1 \mathrm{~d}^{+/-}$mice exhibited lower percentage of OT-II cell proliferation (30.02 $\pm 2.73 \%)$. However, stronger proliferation of OT-II cells was observed in TGF- $\beta_{2-}$ treated $\mathrm{pM} \varphi$ from $\mathrm{CD} 1 \mathrm{~d}^{-/-}$mice $(48.13 \pm 2.86 \%)$. Similarly, OVA-loaded $\mathrm{pM} \varphi$ from $\mathrm{CD} 1 \mathrm{~d}^{+/-}$mice showed decreased proliferation of OT-II cells $(33.5 \pm 3.44 \%)$ in comparison with $\mathrm{pM} \varphi$ from CD1d ${ }^{-1-}$ mice $(50.13 \pm 1.47 \%)$ in CFSE-dilution assay (Fig. $3 \mathrm{~A}, \mathrm{~B})$. IFN- $\gamma$ and IL-4 are widely used markers of $\mathrm{CD} 4^{+} \mathrm{T}$ cell effector function in immune regulation (15). ELISA measurements of IFN- $\gamma$ in culture supernatants revealed that both $\mathrm{CD} 1 \mathrm{~d}^{+/-}$

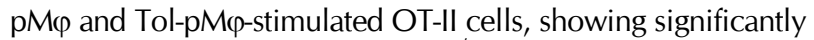
lower IFN- $\gamma$ production than CD1d ${ }^{-/-} \mathrm{pM} \varphi$ and Tol-pM $\varphi$-stimulated OT-II cells, respectively (Fig. 3C). Neither pM $\varphi$ nor TolpM $\varphi$-stimulated OT-II produced measurable levels of IL-4 (data not shown). These results suggest that the presence of CD1drestricted NKT cells might be a factor conferring the ability of $\mathrm{pM} \varphi$ to attenuate $\mathrm{CD} 4^{+} \mathrm{T}$ cell activation.

Differential CD4 T cell responses were observed upon stimulation with antigen-loaded $\mathrm{pM} \varphi$ matured in environments with differential CD1d expression. Therefore, we determined whether DCs from peritoneum/macrophages and DCs from other tissues had similar differential characteristics depending on CD1d expression. Splenic DCs and splenic $M \varphi$ showed no significant differences in CD1d-dependent CD80 or CD86 expression (data not shown). $\mathrm{CD}_{1 \mathrm{~d}^{-1-}}$ peritoneal dendritic cells (pDCs) showed no increase in CD4 T cell stimulation compared to CD1d ${ }^{+/-}$ pDCs either in CFSE dilution assays. These results suggest that iNKT cell-mediated tolerogenicity of APCs is CD1d-dependent
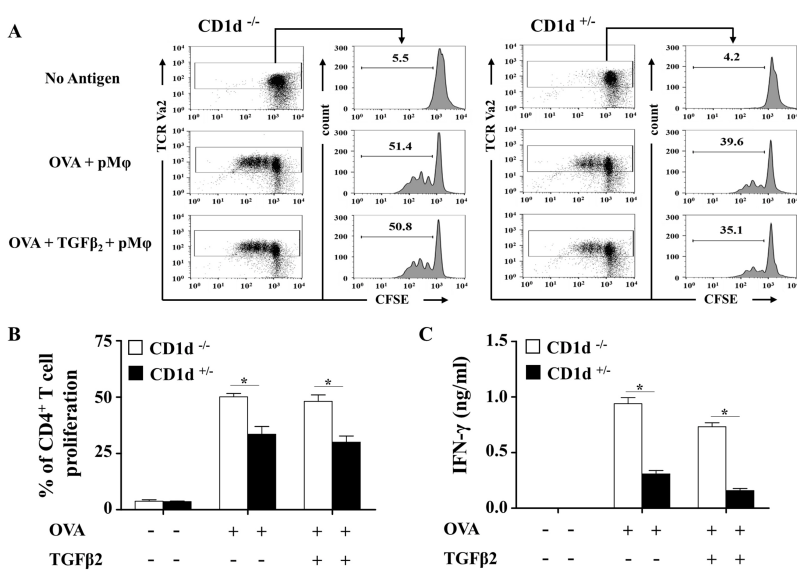

Fig. 3. Inhibitory effects of $C D 1 d^{+} p M \varphi$ on OVA-specific $C D 4^{+} \mathrm{T}$ cell activation. $\mathrm{pM} \varphi$ from $\mathrm{CD}_{1 \mathrm{~d}^{+-}}$and $\mathrm{CD} 1 \mathrm{~d}^{-1-}$ mice were loaded with or without OVA protein, treated with TGF- $\beta_{2}$ if necessary, and co-cultured for $72 \mathrm{~h}$ with CFSE-labeled CD4 ${ }^{+}$T cells from OVAprimed OT-II mice. (A) CFSE profiles of OT-II cell. Histogram shows CFSE profile of TCRV $2^{+}$-gated cells; (B) Percentages of proliferating $\mathrm{CD}^{+}{ }^{+} \mathrm{T}$ cells gated on TCRV $\alpha 2^{+}$cells; (C) Supernatants from cocultures were collected and levels of IFN- $\gamma$ were analyzed using ELISA. Data are representatives of four independent experiments. $* * * P<0.001 ; * * P<0.01 ; * P<0.05$ (Student's t-test). and uniquely evident in $\mathrm{pM} \varphi$.

\section{$\mathrm{CD}^{+} \mathrm{d}^{+}$peritoneal macrophages exhibit tolerogenic effects in a CIA model of CD1d KO host}

We have previously shown that iNKT cells are critical for the induction of Tol-APC-mediated suppression of CIA (14). Thus, we further investigated whether the tolerizing potential was an intrinsic character of $\mathrm{pM} \varphi$ rather than an acquired phenotype following interactions with iNKT cells during immune responses. To exclude iNKT cells' involvement, we adoptively transferred $\mathrm{CD}_{1 d^{+/-}}$Tol-pM $\varphi$ or CD1d ${ }^{-1-}$ Tol-pM $\varphi$ cells into ClA-induced CD1d KO DBA1 mice that lacked iNKT cells. When disease progression in mice was compared, treatments by $\mathrm{CD}_{1} \mathrm{~d}^{+/-}$ Tol-pM $\varphi$ showed significantly reduced percentages of incidence (Fig. $4 \mathrm{~A}, \mathrm{n}=4-5$ mice) and clinical scores $(4.8 \pm 1.8$ vs. $7.4 \pm$ 2.0 at day 48$)$ compared to treatments by $\mathrm{CD} 1 \mathrm{~d}^{-1-} \mathrm{Tol}-\mathrm{pM} \varphi$ (Fig. 4A). These data validated the ability of CD1d ${ }^{+/-}$Tol-pM $\varphi$ to ameliorate $\mathrm{ClA}$ by attenuating $\mathrm{CD}^{+}{ }^{+} \mathrm{T}$ cell activation. In parallel, we compared effects of $\mathrm{pM} \varphi$ in $\mathrm{CD}_{1 \mathrm{~d}^{+-}}$and $\mathrm{CD} 1 \mathrm{~d}^{-/-}$mice with CIA. CD1d ${ }^{+/-}$pM $\varphi$ showed significantly lower incidence and severity of arthritis than those of $\mathrm{CD}_{1 \mathrm{~d}^{-/-}} \mathrm{pM} \varphi(6.0 \pm 1.1$ vs. $9.7 \pm 0.7$ at day 50 ; Fig. 4 B). Taken together with data from experiments using Tol-pM $\varphi$, these results clearly demonstrate that $\mathrm{CD} 1 \mathrm{~d}$-expressing $\mathrm{pM} \varphi$ have intrinsic immunosuppressive functions, suggesting that iNKT cells possibly can confer these tolerogenic activities during the development of $\mathrm{pM} \varphi$.
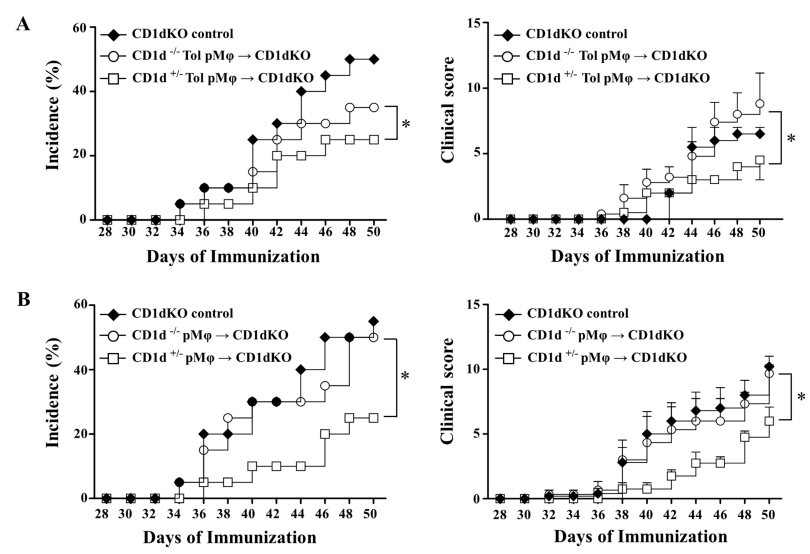

Fig. 4. $C D 1 d^{+} p M \varphi$ display tolerogenic phenotypes in CIA-induced CD1d KO hosts. CD1d KO mice were immunized by i.d. injections of $100 \mu \mathrm{g}$ of chicken Cll emulsified with an equal volume of CFA at the base of the tail to develop CIA. On day 21, mice were i.d. boosted with $100 \mu \mathrm{g}$ of IFA. Seven days later, mice received i.v.

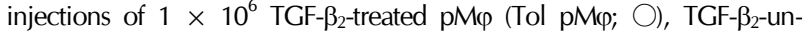
treated (pM $\varphi ; \square)$, or PBS transfer as CIA control (A). (A) Incidence and clinical scores of arthritis in groups received Tol $\mathrm{pM} \varphi ;(B)$ Incidence and Clinical scores of arthritis in groups received $\mathrm{pM} \varphi$. Each paw was scored from 0 to 5 according to the severity of arthritis, with a maximal cumulative score of 20 . Results are representatives of three independent experiments. Data are presented as mean inflammatory scores $(0-5) \pm$ standard errors of the mean (SEM; 4-5 mice per group); $* P<0.05$ (Student's t-test). 


\section{DISCUSSION}

Selective moderation of macrophage activation remains an attractive therapeutic approach to diminish local and systemic inflammation for preventing irreversible joint damage because the activation of monocytic lineage is not locally restricted, but extended to systemic parts of the mononuclear phagocyte system (16). Activation of APCs following interactions with iNKT cells may occur during immune activation and quiescence. Thus, interactions of iNKT cells with APCs might have proinflammatory or tolerizing outcomes, suggesting that effector and regulatory iNKT cells can coexist (6).

Induction of antigen-specific tolerance is critical for preventing autoimmunity and maintenance of immune tolerance. TGF- $\beta_{2^{-}}$ treated Tol-APCs are known to induce anterior chamber-associated immune deviation (ACAID)-like tolerance (17). ACAID is a peripheral tolerance that protects eye tissues from destructive inflammation. It is mainly mediated by eye-derived APCs and B cells (18), $\alpha \beta$ T cells (19), and NKT cells (20). Earlier data have shown that ACAID tolerance can be induced by Tol-APCs by inhibiting $\mathrm{ClA}$ and its related systemic immune responses in murine arthritis models following a single injection of Tol-APCs where iNKT cells are associated with a shift from Th1 to Th2 responses of Cll-specific T and B cells (14).

CD1d antigen presentation is defective in some patients with RA, showing reduced iNKT cell numbers and altered functions (21). APCs express functional CD1d molecules on their surface to retain suppressive capacities following burn injury-induced immune suppression (22). B cells expressing CD1d are also required for iNKT cells to facilitate enhanced antibody production (23). The ensuing mechanism is probably restricted to T-independent antigens (24). Sonoda et al. (20) have also demonstrated that CD1d on APCs is required to generate immunologic tolerance and shown that CD1d-positive APCs could induce iNKT cell-dependent efferent $T$ cell tolerance of antigens inoculated via eyes. Although the requirement of CD1d expression on APCs in previous studies has highlighted the direct role of iNKT cells, results of the present study using iNKT cell-deficient mice suggest that in addition to direct interactions of APCs with iNKT, maturation of APCs in the presence of iNKT cell also contributes to the suppressive phenotype of $\mathrm{pM} \varphi$, thereby suppressing CIA.

Our in vivo studies showed that both $\mathrm{CD}_{1 \mathrm{~d}^{+-}} \mathrm{pM} \varphi$ and Tol-pM $\varphi$ contributed to lower clinical scores and incidences in iNKT cell-deficient CIA model, thus ruling out the direct action of iNKT cells on these APCs. LPS-induced expression of costimulatory molecules and cytokine secretions corroborated suppressive or tolerogenic capacities of $\mathrm{CD}_{1 \mathrm{~d}^{+/-}} \mathrm{pM} \varphi$. Because we ruled out the direct contribution of iNKT cells at the time of antigen recognition on $\mathrm{pM} \varphi$ using $\mathrm{CD} 1 \mathrm{~d}^{-/-}$hosts where iNKT cells were deficient, long-term education by iNKT cells during development of donor $\mathrm{CD} 1 \mathrm{~d}^{+/-} \mathrm{pM} \varphi$ might have led to intrinsic immunosuppressive properties of $\mathrm{pM} \varphi$. Because of this cell intrinsic immunosuppressive property of $\mathrm{pM} \varphi$, we could not exclude the possibility that CD1d expression itself on $\mathrm{pM} \varphi$ may exert an immunosuppressive effect by some unknown mechanisms.

In summary, our results revealed that CD1d-expressing $\mathrm{pM} \varphi$ suppressed $\mathrm{CD}^{+}{ }^{+} \mathrm{T}$ cell proliferation after coculture, leading to down-regulation of Ag-specific IFN- $\gamma$ production by CD4 T cells. We also observed lower CIA severity both in $\mathrm{CD}_{1 \mathrm{~d}^{+/-}}$and $\mathrm{CD}_{1 \mathrm{~d}^{-1-}}$ recipient mice after adoptive transfer of CD1d ${ }^{+/-} \mathrm{pM} \varphi$, but not by such transfer of CD1d ${ }^{-/-} \mathrm{pM} \varphi$. These observations suggest that $\mathrm{CIA}$ suppression is mediated by $\mathrm{CD} 1 \mathrm{~d}$-expressing $\mathrm{pM} \varphi$ and that tolerogenicity of $\mathrm{pM} \varphi$ is a cell-intrinsic property probably conferred by iNKT cells during $\mathrm{pM} \varphi$ development. Emerging evidence indicates that environmental factors can shape the identity of tissue resident macrophages. Therefore, earlier education by NKT cells potentially contributes to tolerogenic programs of $\mathrm{pM} \varphi$, thus influencing the course of the $\mathrm{CIA}$.

\section{MATERIALS AND METHODS}

WT C57BL/6 mice were purchased from Orient Bio (Seongnamsi, Gyeonggi-do, Korea). C57BL/6 CD1d ${ }^{-1-}$ mice used in this study were provided by Albert Bendelac's lab (3). All animal experiment protocols adapted in this study were approved by the Institutional Animal Care and Use Committee of Korea University (KUIACUC-2018-25). DBA/1 mice were purchased from Charles River Laboratories (Japan) and backcrossed more than eight times with C57BL/6 CD1d ${ }^{-1-}$ mice to generate DBA1CD1d ${ }^{-1-}$ mice. Mice with DBA background were used for in vivo arthritis induction. All other experiments were performed using mice with C57BL/6 background. OT-II TCR transgenic (Tg) mice were purchased from the Jackson Laboratory (Bar Harbor, ME, USA). Complete Freund's adjuvant (CFA), Mycobacterium tuberculosis, ovalbumin (OVA), and carboxyfluorescein succinimidyl ester (CFSE), a fluorescent cell staining dye, were purchased from Sigma-Aldrich (St. Louis, MO, USA). Chicken OVA ${ }_{323-339}$ peptide ( $\mathrm{H}-2^{\mathrm{d}}$ restricted; amino acid sequence ISQAVHAAHAEINEAGR) was purchased from GenScript (Piscataway, NJ, USA). Cells were cultured in Roswell Park Memorial Institute (RPMI) 1640 medium (Life Technologies, Rockville, MD, USA) supplemented with 2-mM L-glutamine, $50-\mathrm{U} / \mathrm{ml}$ penicillin, $50-\mu \mathrm{g} / \mathrm{ml}$ streptomycin, $10-\mu \mathrm{g} / \mathrm{ml}$ gentamicin sulfate, $50-\mu \mathrm{M} \beta$-mercaptoethanol (Life Technologies), and $10 \%$ heat-inactivated FBS (Hyclone, Logan, UT, USA). IL-4 and IFN- $\gamma$ concentrations were measured using OPTEIA Mouse IL-4 and IFN- $\gamma$ enzyme-linked immunoassay kits (BD Pharmingen, San Diego, CA, USA), respectively.

\section{In vitro generation of tolerogenic $\mathrm{pM} \varphi$}

Peritoneal exudate cells (PECs) were prepared after collecting peritoneal washes of C57BL/6 or DBA 1 mice at three days after intraperitoneal (i.p.) injections of $3 \mathrm{ml}$ of $3 \%$ thioglycolate solution (Sigma-Aldrich). Isolated PECs (pM $\varphi$ ) were then cultured overnight in a serum-free medium. For the generation of TolpM $\varphi, 5 \mathrm{ng} / \mathrm{ml}$ TGF- $\beta_{2}$ (R\&D systems, Minneapolis, MN, USA) was added into the culture medium. After culture, $\mathrm{pM} \varphi$ and Tol-pM $\varphi$ 
were washed three times with phosphate buffer saline (PBS). Remaining adherent cells were subjected to cold stress at $4^{\circ} \mathrm{C}$ in PBS for $2 \mathrm{~h}$ and then collected by vigorous pipetting. Cells were then washed three times with PBS and resuspended in PBS to cell density of $1 \times 10^{6} \mathrm{cells} / \mathrm{ml}$ (17). Subsequently, cells were stained with anti-CD11b and CD11c antibodies. Typical $\mathrm{pM} \varphi$ phenotypes $\left(\mathrm{CD} 11 \mathrm{~b}^{+} \mathrm{CD} 11 \mathrm{c}^{+}\right)$were confirmed in more than $90 \%$ of cells. To transfer pM $\varphi$ into ClA-induced mice, $100 \mu$ l of cell suspensions containing $1 \times 10^{6}$ cells Cll in incomplete Freund's adjuvant (IFA; Sigma-Aldrich) was injected into tail veins at 7 days after the second immunization.

\section{$\mathrm{CIA}$ induction and assessments of clinical scores}

DBA1 1 mice were immunized intradermally (i.d.) at the base of the tail with $100 \mu \mathrm{g}$ of chicken type CII (Sigma-Aldrich) emulsified with an equal volume $(50 \mu \mathrm{l})$ of CFA (Sigma-Aldrich) according to a standard method (25). Mice were boosted by i.d. injections with $100 \mu \mathrm{g}$ of Cll emulsified in IFA on day 21. Seven days later, mice received intravenous (i.v.) injections of either $\mathrm{pM} \varphi$ or Tol-pM $\varphi$ at $1 \times 10^{6}$ cells/mouse. Mice were then monitored on alternate days for the development of arthritis until the end of the experiment. Arthritis severity was graded as follows: 0 = normal paws; 1 = edema and erythema in only one digit; 2 = slight edema or erythema in multiple digits; 3 = slight edema involving the entire paw; 4 = moderate edema and erythema involving the entire paw; and 5 = severe edema and erythema involving the entire paw and subsequent ankylosis. Cumulative values were determined for all paws, with a maximum score of 20. Average macroscopic scores were then calculated.

\section{In vitro OVA-specific $\mathrm{CD4}^{+} \mathrm{T}$ cell responses}

Effector $\mathrm{CD}^{+}{ }^{+}$T cells were obtained from OT-II transgenic mice immunized subcutaneously (s.c.) using $100 \mu \mathrm{g}$ of OVA protein in CFA. After two weeks, primed $\mathrm{CD}^{+}{ }^{+} \mathrm{T}$ cells were sorted using antibody-coated magnetic beads and labeled with $5 \mu \mathrm{M}$ CFSE. Purified $\mathrm{CD}^{+}{ }^{+} \mathrm{T}$ cells $\left(5 \times 10^{5}\right.$ cells/well $)$ were then added into 24-well plates containing OVA-loaded pM $\varphi$ or Tol$\mathrm{pM \varphi}\left(5 \times 10^{4}\right.$ cells/well). After three days, culture supernatants were collected and analyzed for cytokines using enzyme-linked immunosorbent assay (ELISA) kits. Cultured cells were then harvested for proliferation assays using CFSE dilution.

\section{Measurements of costimulatory molecules and cytokine secretions}

In addition to $\mathrm{pM} \varphi$, splenic macrophages and dendritic cells were isolated using anti CD11b- and CD11c-magnetic beads through magnetic-activated cell sorting (MACS). Expression levels of CD11c, CD11b, F4/80, CD80 (B7-1), CD86 (B7-2), CD1d (1B1), CD206, and MHC II (IA $\left.{ }^{b}\right)$ were analyzed using a FACS Verse flow cytometer (BD). Culture supernatants were then assayed for IL-6, IL-10, and TNF- $\alpha$ levels using relevant enzymelinked immunoassay kits (BD Pharmingen, San Diego, CA, USA) after stimulation with LPS from Escherichia coli 055:B5 at various concentrations.

\section{Flow cytometric analysis}

Cells were stained with anti-FCR- $\gamma$ mAb (2.4G2) at $4^{\circ} \mathrm{C}$ for 20 min in FACS staining buffer (PBS containing 0.1\% BSA and $0.01 \%$ sodium azide). Cells were then stained with the following mAbs (BD Biosciences) for an additional 30 min: TCR $\beta$ (H57), CD4 (RM4-5), CD8 $\alpha$ (53-6.7), IFN- $\gamma$ (XMG1.2), and IL-4 (11B11). Stained cells were then analyzed using a FACS Calibur or FACS Verse and analyzed with Flowjo program.

\section{Statistical analysis}

Differences in clinical data between groups were assessed by Kruskal-Wallis test followed by Dunn's Multiple comparison post-test (clinical score) or Student's t-test using Prism 7 software (GraphPad Software, La Jolla, CA, USA). Statistical significance was considered at $\mathrm{P}<0.05$.

\section{ACKNOWLEDGEMENTS}

This work was supported by a grant (NRF-2018R1A2A2A050 23297) of the Basic Science Research Program of the National Research Foundation of Korea and a grant (K2010761) from Korea University. We thank crews of Geyrim Experimental Animal Resource Center for their assistance in animal handling and maintenance.

\section{CONFLICTS OF INTEREST}

The authors have no conflicting interests.

\section{REFERENCES}

1. Hughes FM Jr, Pringle CM and Gorospe WC (1991) Production of progestin-stimulatory factor(s) by enriched populations of rat T and B lymphocytes. Biol Reprod 44, 922-926

2. Weiss A, Irving BA, Tan LK and Koretzky GA (1991) Signal transduction by the T cell antigen receptor. Semin Immunol 3, 313-324

3. Bendelac A, Rivera MN, Park SH and Roark JH (1997) Mouse CD1-specific NK1 T cells: development, specificity, and function. Annu Rev Immunol 15, 535-562

4. Bleicher PA, Balk SP, Hagen SJ, Blumberg RS, Flotte TJ and Terhorst $C$ (1990) Expression of murine CD1 on gastrointestinal epithelium. Science 250, 679-682

5. Godfrey DI, MacDonald HR, Kronenberg M, Smyth MJ and Van Kaer L (2004) Opinion - NKT cells: what's in a name? Nat Rev Immunol 4, 231-237

6. Hegde S, Fox L, Wang XH and Gumperz JE (2010) Autoreactive natural killer $\mathrm{T}$ cells: promoting immune protection and immune tolerance through varied interactions with myeloid antigen-presenting cells. Immunology 130, 471-483

7. Chiba A, Kaieda S, Oki S, Yamamura T and Miyake S (2005) The involvement of V(alpha)14 natural killer T cells in the pathogenesis of arthritis in murine models. Arthritis Rheum 52, 1941-1948

8. Coppieters K, Van Beneden K, Jacques P et al (2007) A 
single early activation of invariant NK T cells confers longterm protection against collagen-induced arthritis in a ligandspecific manner. J Immunol 179, 2300-2309

9. Ko HJ, Lee JM, Kim YJ, Kim YS, Lee KA and Kang CY (2009) Immunosuppressive myeloid-derived suppressor cells can be converted into immunogenic APCs with the help of activated NKT cells: an alternative cell-based antitumor vaccine. J Immunol 182, 1818-1828

10. Kojo S, Seino K, Harada M et al (2005) Induction of regulatory properties in dendritic cells by Valpha14 NKT cells. J Immunol 175, 3648-3655

11. Teige A, Bockermann R, Hasan M, Olofsson KE, Liu Y and Issazadeh-Navikas S (2010) CD1d-dependent NKT cells play a protective role in acute and chronic arthritis models by ameliorating antigen-specific Th1 responses. J Immunol 185, 345-356

12. Teige A, Teige I, Lavasani S et al (2004) CD1-dependent regulation of chronic central nervous system inflammation in experimental autoimmune encephalomyelitis. J Immunol 172, 186-194

13. Brandes M, Willimann K and Moser B (2005) Professional antigen-presentation function by human gamma delta $T$ cells. Science 309, 264-268

14. Jung S, Park YK, Shin JH et al (2010) The requirement of natural killer T-cells in tolerogenic APCs-mediated suppression of collagen-induced arthritis. Exp Mol Med 42, 547554

15. Nakamura $T$, Kamogawa $Y$, Botomly $K$ and Flavell RA (1997) Polarization of IL-4 and IFN-gamma-producing CD4+ T cells following activation of naive CD4 + T cells. J Immunol $158,1085-1094$

16. Kinne RW, Brauer R, Stuhlmuller B, Palombo-Kinne E and Burmester GR (2000) Macrophages in rheumatoid arthritis.
Arthritis Res 2, 189-202

17. Wilbanks GA, Mammolenti M and Streilein JW (1991) Studies on the induction of anterior chamber-associated immune deviation (ACAID). II. Eye-derived cells participate in generating blood-borne signals that induce ACAID. J Immunol 146, 3018-3024

18. D'Orazio TJ and Niederkorn JY (1998) Splenic B cells are required for tolerogenic antigen presentation in the induction of anterior chamber-associated immune deviation (ACAID). Immunology 95, 47-55

19. Xu Y and Kapp JA (2001) Gammadelta T cells are critical for the induction of anterior chamber-associated immune deviation. Immunology 104, 142-148

20. Sonoda KH, Exley M, Snapper S, Balk SP and SteinStreileinl J (1999) CDI reactive NKT cells are required for development of systemic tolerance through an immune privileged site. J Exp Med 190, 1215-1226

21. Kojo S, Tsutsumi A, Goto D and Sumida T (2003) Low expression levels of soluble CD1d gene in patients with rheumatoid arthritis. J Rheumatol 30, 2524-2528

22. Palmer JL, Tulley JM, Kovacs EJ, Gamelli RL, Taniguchi M and Faunce DE (2006) Injury-induced suppression of effector T cell immunity requires CD1d-positive APCs and CD1d-restricted NKT cells. J Immunol 177, 92-99

23. Lang GA, Devera TS and Lang ML (2008) Requirement for CD1d expression by B cells to stimulate NKT cell-enhanced antibody production. Blood 111, 2158-2162

24. Lang GA, Exley MA and Lang ML (2006) The CD1d-binding glycolipid alpha-galactosylceramide enhances humoral immunity to T-dependent and T-independent antigen in a CD1ddependent manner. Immunology 119, 116-125

25. Brand DD, Latham KA and Rosloniec EF (2007) Collageninduced arthritis. Nat Protocols 2, 1269-1275 